\title{
Puberty and Body Composition
}

\author{
Roger M. Siervogel Ellen W. Demerath Christine Schubert \\ Karen E. Remsberg William Cameron Chumlea Shumei Sun \\ Stefan A. Czerwinski Bradford Towne
}

Lifespan Health Research Center, Department of Community Health, Wright State University School of Medicine, Dayton, Ohio, USA

\section{Key Words}

Pubescence $\cdot$ Puberty $\cdot$ Body composition - Total body fat · Fat-free mass - Bone mineral content - Bone mineral density · Body mass index $\cdot$ Children · Longitudinal study

\begin{abstract}
Body composition during puberty is a marker of metabolic changes that occur during this period of growth and maturation, and, thus, holds key information regarding current and future health. During puberty, the main components of body composition (total body fat, lean body mass, bone mineral content) all increase, but considerable sexual dimorphism exists. Methods for measuring body composition (e.g. densitometry and dual-energy $X-$ ray absorptiometry) and degree of maturity will be discussed in this review. Components of body composition show age-to-age correlations (i.e. 'tracking'), especially from adolescence onwards. Furthermore, adipose tissue is endocrinologically active and is centrally involved in the interaction between adipocytokines, insulin and sexsteroid hormones, and thus influences cardiovascular and metabolic disease processes. In conclusion, pubertal body composition is important, not only for the assessment of contemporaneous nutritional status, but also for
\end{abstract}

being linked directly to the possible onset of chronic disease later in life and is, therefore, useful for disease risk assessment and intervention early in life.

Copyright $\odot 2003$ S. Karger AG, Basel

\section{Introduction}

During puberty, dramatic hormonal fluctuations as well as a rapid growth in body size occur and are accompanied by marked changes in body composition. While body composition can refer to many different features and be assessed using different methods, here we focus primarily on a few body components, including total body fat (TBF) mass, fat-free mass (FFM) and bone mineral content (BMC). Other related measures of body composition include percentage body fat, lean body mass (FFM $\mathrm{BMC}$ ), bone mineral density and total body water. In addition, body composition in other contexts can be considered in terms of the masses of various tissues or organs, body cell mass, fat-free extracellular solids, and extracellular water, as well as by its chemical composition (e.g. potassium, nitrogen etc.) [1]. Pubertal development involves the chemical maturation of body tissues, including the amount and distribution of adipose tissue, and increases in bone mass and fat-free lean tissue mass.

\begin{tabular}{ll}
\hline KARGER & ( ) 2003 S. Karger AG, Basel \\
0301-0163/03/0607-0036\$19.50/0 \\
$\begin{array}{l}\text { Fax +4161306 1234 } \\
\begin{array}{l}\text { E-Mail karger@karger.ch } \\
\text { www.karger.com }\end{array}\end{array}$ & $\begin{array}{l}\text { Accessible online at: } \\
\text { www.karger.com/hre }\end{array}$
\end{tabular}

Prof. R.M. Siervogel

Lifespan Health Research Center, Wright State University School of Medicine

3171 Research Boulevard

Dayton, OH 45420 (USA)

Tel. +1 937775 1415, Fax +1 937775 1456, E-Mail roger.siervogel@wright.edu 
In this review, we will begin by providing an overview of the general cross-sectional changes in body composition in boys and girls during puberty. We will then discuss common measures of body composition and methods of assessing body composition and pubertal development. Finally, the importance of body composition during puberty will be considered, including the endocrinological role of adipose tissue, secular increases in adiposity, and the serial interactions between body composition and the process of maturation.

\section{Patterns of Change in Body Composition during Puberty}

There is significant sexual dimorphism in puberty, not only in the timing of pubertal events, but also in body composition [2-4]. Both sexes experience rapid increases in TBF, although the proportion of body fat increases more slowly in boys as a result of a simultaneous rapid increase in FFM [5]. Data from girls in the Fels Longitudinal Study show that levels of TBF increase at a fairly constant rate from a mean of approximately $5.5 \mathrm{~kg}$ at 8 years of age to about $15 \mathrm{~kg}$ at 16 years, after which the rate of increase slows considerably. In boys, there is an increase in TBF from a mean of approximately $5.0 \mathrm{~kg}$ at 8 years to about $11.0 \mathrm{~kg}$ at 14 years, after which TBF falls to approximately $9.0 \mathrm{~kg}$ at 16 years and subsequently reaches a plateau. The patterns of pubertal change in males and females for FFM are, to some extent, reversed. In girls, FFM increases until around the age of 15 years, and then remains relatively unchanged. In boys, however, FFM increases steadily between the ages of 8 and 18 years, with a more rapid increase between 12 and 15 years of age.

There are significant increases in the energy requirements of children, associated with changes in body composition. These increases vary, are sex-dependent, and occur at an early stage of puberty as a result of increases in physical capacities and energy expenditure [6]. The differences between the sexes that emerge in metabolic rate and physical strength are explained largely by the greater amount of FFM in boys [6]. Furthermore, the hormonal changes associated with the onset of puberty in boys, such as increased testosterone and growth hormone metabolism, may account for the larger energy expenditure found in pubertal compared with pre-pubertal boys.

\section{Methods for Measuring Body Composition}

Methods used to estimate and measure the fat, lean and bone mineral components of body composition range from relatively simple field methods using anthropometrics, such as height and weight, to highly sophisticated approaches requiring specialized laboratories and equipment (e.g. neutron activation). The methods generally used today include anthropometrics, hydrodensitometry, air displacement plethysmography, dual-energy X-ray absorptiometry (DXA), bioelectric impedance, deuterium oxide dilution, magnetic resonance imaging (MRI) and computed tomography $[1,7]$. The last two methods have been used in children and adults and tend to be well tolerated by both; however, the higher radiation doses required for computed tomography make this method less desirable in some contexts.

\section{Anthropometry}

Apart from the basic measures of height and weight, the introduction of skinfold calipers and other anthropometric equipment in the 1950s allowed for reliable measurement of subcutaneous fat in different regions of the body, as well as the measurement of body widths and circumferences. These measurements can then be used in population-specific prediction equations to estimate various components of body composition. For example, midarm and mid-thigh circumferences can be used to estimate muscle mass in the absence of more direct methods. Waist and hip circumferences can be used to characterize the distribution of body fat on the torso - an important independent risk factor for heart disease and diabetes mellitus. Anthropometric methods, as measures of subcutaneous fat and rough estimates of muscle mass, are, however, indirect in their ability to estimate total body composition. In addition, considerable training to take measurements as well as to monitor patients is required to achieve sufficiently high reliability for scientific research purposes.

Body mass index (BMI) is easy to obtain and is therefore a commonly used index of body composition (adiposity). It is defined as weight in kilograms divided by the square of stature (standing height) in metres. BMI is often used to determine overweight and obesity in the clinical environment, usually by comparison of an individual to age- and sex-specific percentiles from a reference population [8]. In this context, a variety of recommendations have been made, such as using specific percentiles to define overweight and obesity [9] or setting cut-off values at childhood percentiles that correspond to the adult 
values for overweight and obesity - values that are known to be related to morbidity and mortality [10]. The adult BMI values that characterize that individuals are overweight and obese, 25 and $30 \mathrm{~kg} / \mathrm{m}^{2}$, respectively, correspond to the 80th and 95th percentiles of the US National Center for Health Statistics reference values for 18-yearold children $[11,12]$. The US Centers for Disease Control and Prevention have recently published new reference childhood growth charts for BMI [8, 13-15].

Although the BMI values are widely applied to both children and adults, there are serious limitations regarding the use of BMI as an index of adiposity in children [16]. BMI in adults is largely independent of stature; it is not, however, independent of stature in children and is quite sensitive to body build [16]. For example, children and youths with undersized legs for their height will have higher BMI values compared with children with longer leg lengths relative to their height. Furthermore, despite high positive correlations between measures of BMI and adiposity, such as TBF and percentage body fat across all age groups, BMI also has a strong positive correlation with FFM in children [5, 17-19]. BMI only has low-to-moderate sensitivity in identifying children with excess TBF or percentage body fat, indicating that the use of BMI to identify children who are overweight is only poor-to-fair $[20,21]$.

\section{Densitometry}

Hydrodensitometry was developed in the early 1960s and uses the difference between body weight measured on dry land and during total water immersion to estimate total body density. Measurement of residual lung volume is necessary to adjust for the buoyancy caused by unexpelled air remaining in the lungs during the test. Total body density, and the known constant density of adipose tissue, may then be used to calculate TBF, FFM and percentage body fat. Hydrodensitometry has remained the 'gold standard' of body composition estimation since the 1960s, because of its ability to measure total body density accurately and precisely. Limitations of hydrodensitometry, however, include cumbersome equipment (i.e. a water tank), participant performance and discomfort (i.e. water immersion) and a restriction to a two-component view of body composition (fat mass and FFM) [7].

Air displacement plethysmography measures changes in gas pressure when a patient enters a closed chamber, resulting in the displacement of air [22, 23]. The volume of air displaced is directly related to the total body volume of the patient, allowing for an estimation of total body density, via the measurement of body mass. This method requires adjustments for body temperature, body surface area and the volume of air exhaled during the test. The resulting total body density estimate can be used to calculate percentage body fat, TBF and FFM.

\section{Dual-Energy X-Ray Absorptiometry}

DXA, which has widespread use in the clinical diagnosis of osteoporosis, uses low-dose radiation to distinguish soft tissue from bone and density variation within soft tissues, and provides estimates of TBF, FFM, lean body mass, $\mathrm{BMC}$, percentage body fat and bone mineral density. Interpretation of DXA data in children requires consideration of bone size, stage of pubertal development, skeletal maturation, ethnicity and body composition [24]. When additional subcomponents of the FFM can be measured, as in the case of bone mass from DXA, they can also be used in conjunction with TBF from hydrodensitometry to generate multi-compartment body composition models.

\section{Other Methods for Measuring Body Composition}

Bioelectrical impedance analysis (BIA) uses tissue resistance to a small electrical charge to estimate total body water and thereby estimates FFM [25]. Deuterium oxide dilution also estimates total body water and, therefore, FFM, but does so more accurately than BIA. Whole body potassium counters detect the natural radioisotope ${ }^{40} \mathrm{~K}$, providing a measure of muscle mass [26]. Finally, methods such as in vivo neutron activation, computed tomography and MRI can provide chemical and spatial models of body composition. Computed tomography and MRI can measure intra-abdominal adipose tissue, a metabolically active fat component shown to be strongly associated with coronary heart disease and diabetes mellitus in adults [27-29].

\section{Measures of Maturation and Puberty}

The main methodological issues in research on puberty are in determining when it begins, how it progresses and how it should be measured. Common measures of maturation include sexual maturation indicators (e.g. Tanner stages and age at menarche), measures of bone growth and epiphyseal fusion (e.g. skeletal age assessment), and landmarks of physical growth (e.g. age at peak height velocity $[\mathrm{PHV}])$. 
Fig. 1. Example of a stature velocity curve for an individual as described by a triple logistic curve. Growth landmarks shown include early childhood and pre-pubertal minimum height velocity (MHV) and adolescent peak height velocity (PHV).

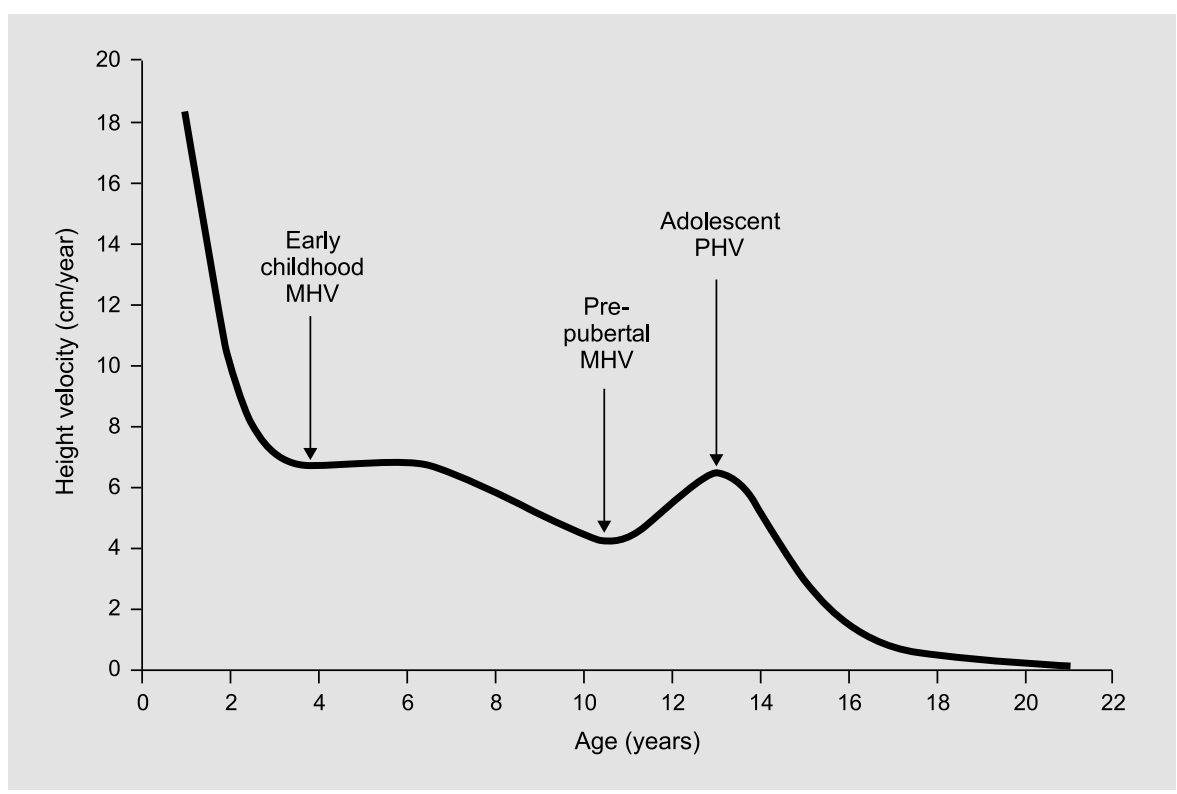

\section{Sexual Maturation}

Tanner stages of sexual maturation are based on pubic hair development for boys and girls, breast development for girls and genital development for boys. The stages progress from pre-puberty (stage 1), through puberty (stages 2-4) to post-puberty (stage 5). The median age at onset of stage 2 (the beginning of puberty) varies depending on the maturity characteristic and sex of the child. For example, for children in the USA, the median age at onset of stage 2 in boys is 10.03 years for genital development and 11.98 years for pubic hair development [30]. The corresponding median age for onset of stage 2 in girls is 10.38 years for breast development and 10.57 years for pubic hair development [30]. The variation in the age of onset between the two indicators for boys and girls makes the definition of puberty using Tanner stages difficult. Age at menarche is also a pubertal landmark in girls and there is considerable population variation in the age at onset. The current average age at onset for girls in the USA is 12.43 years, with the ages at onset of menarche for Caucasian, AfricanAmerican and Mexican-American girls being 12.55, 12.06 and 12.25 years, respectively [31].

\section{Skeletal Maturation}

The skeletal age of an individual can be assessed using radiographs of the hand and wrist, or the knee. The Fels method for skeletal age assessment of the hand and wrist [32] uses grades determined for degree of bone ossification, shape, and fusion of the carpals, epiphyses of the metacarpals, and the phalanges of digits I, III and V. The Fels method is widely used in a variety of ongoing pharmaceutical trials involving children in the USA and is also being used in a genetic epidemiological study of skeletal maturation [33]. Relative skeletal age (i.e. skeletal age chronological age) can be used as a measure of the degree to which an individual is skeletally advanced or delayed for their age. Skeletal maturation is associated with body composition and can be used to identify slow- and fastmaturing children.

\section{Growth and Maturation}

Measurements of growth in stature can also serve as indicators of maturation. When long-term serial data are available for an individual, a triple logistic model or other statistical models can be fitted to the patient's serial stature data to calculate parameters of this physical growth curve. The height velocity curve of a patient is shown in figure 1. Curve parameters can be used to identify and quantify growth landmarks, for example, early childhood minimum height velocity (MHV), age at early childhood MHV, pre-pubertal MHV, age at pre-pubertal MHV, $\mathrm{PHV}$ and age at PHV.

Age at PHV is inversely related to the magnitude of PHV in both sexes [34], in that children with an early adolescent growth spurt exhibit a higher PHV than children with a later spurt. Boys who have a later growth spurt have been reported to accrue more bone mineral and lean mass and are taller at the age of PHV, compared with boys with 
earlier growth spurts [34]. Weight and fat mass, however, do not appear to differ between maturity groups at the age at PHV in either sex [34]. At a given chronological age, children who are more mature tend to be taller and heavier than less mature children. Indeed, children who have a more rapid rate of sexual maturation tend to have a higher risk of obesity in adulthood $[35,36]$.

\section{Importance of Body Composition during Puberty}

Monitoring body composition during puberty is important because many aspects of body composition during this period are predictive of subsequent measures of these traits in adulthood (i.e. body composition 'tracks') $[37,38]$. Adipose tissue, a major component of body composition, is endocrinologically active and has important interactions with sex-steroid hormones [39, 40]. Furthermore, certain aspects of body composition and their changes during puberty are risk factors for a variety of common, multi-factorial adult diseases, including cardiovascular disease, diabetes mellitus, obesity and osteoporo$\operatorname{sis}[4,8,41-43]$.

\section{Tracking of Body Composition from Childhood into Adulthood}

Serial assessment of body composition during puberty allows for the study of changes in values across the different age groups. Tracking can be measured by determining the correlation between a trait measured in the same individual at two or more points in time. Tracking of weight is slight-to-moderate from birth to childhood and adolescence [44], while tracking correlations are moderate-tostrong from childhood to adulthood. Correlations of childhood BMI with adult BMI are low, but increase with age during adolescence [37]. For example, among children aged 8 to 13 years with a BMI greater than the 95 th percentile, $33 \%$ of boys and $50 \%$ of girls continued to be obese as adults, whereas for adolescents aged 13 to 18 years with a BMI greater than the 95 th percentile, $50 \%$ of males and $66 \%$ of females were obese in adulthood [37]. Similarly, birth weight and infant weight have low positive correlations with BMI later in life. These relationships are weak $(r<0.20)$, and so weight status in infancy holds little predictive value at the individual level. Body composition components show considerable tracking from childhood onwards. Tracking correlations for TBF and FFM from early childhood into adulthood are low but significant $[45,46]$, whereas tracking correlations for TBF and FFM from post-puberty to adulthood are high [3]. These high tracking correlations from adolescence onwards show the importance of understanding the changes in body composition that are related to the timing and progression of puberty because they can predict future body composition.

\section{Adipose Tissue Is Endocrinologically Active}

Another important aspect of body composition during puberty is that adipose tissue is active as an endocrine organ. Adipocyte-secreted proteins are produced in response to a variety of changes in metabolic status [39]. Adipocytokines (adipose tissue-derived molecules) include leptin, adiponectin and resistin. These molecules are involved in lipid and lipoprotein metabolism, vascular homeostasis and fibrinolytic function, and some have potent pro- and anti-inflammatory properties [39].

Leptin functions as a regulator of energy balance [47] by interacting with several neuropeptides to inhibit food intake, and affecting the expenditure of energy. Leptin also appears to be involved in mediating various endocrine mechanisms (e.g. onset of puberty, insulin secretion) and is related to disorders including obesity and polycystic ovary syndrome $[48,49]$. Leptin is primarily synthesized in adipose tissue, but is also synthesized in the stomach, placenta, mammary glands and ovarian follicles, as well as other organs. Leptin is strongly related to TBF, with blood levels of leptin being more strongly correlated with subcutaneous than visceral (intra-abdominal) adipose tissue.

There is a clear sexual dimorphism in circulating concentrations of leptin, with girls having higher serum concentrations of leptin than boys before, during and after puberty, even after the greater adiposity in females is taken into account [50]. Pre-pubertal levels of leptin in girls also predict gains in percentage body fat during puberty [51]. Gonadal steroids are strong candidates for mediators of the sexual dimorphism in leptin concentrations; the situation is, however, more complex. Circulating leptin concentrations during late puberty are significantly affected by sex, after the effects of body composition and circulating concentrations of gonadal steroids are accounted for [40]. Thus, the sexual dimorphism may also reflect direct or interactive effects of other sex-related metabolic variables such as insulin, growth hormone or adipose tissue distribution [40]. Finally, leptin concentration is inversely related to $\mathrm{C}$-reactive protein concentration, a marker of inflammation. The general association of increases in body fat with increases in inflammation indicates that leptin may have anti-inflammatory properties [52].
40

Horm Res 2003;60(suppl 1):36-45
Siervogel/Demerath/Schubert/Remsberg/ Chumlea/Sun/Czerwinski/Towne 
Based on a small, yet detailed, study in children, Roemmich and colleagues [53] showed that pubertal insulin resistance (as measured by the Homeostasis Model Assessment [HOMA]) is associated with body composition. Their results led them to speculate that the accumulation and distribution of fat in the abdominal, visceral, subcutaneous and muscular components of the body may increase insulin resistance during puberty beyond that caused by TBF. In addition, they speculated that serum concentrations of leptin and insulin-like growth factor I (IGF-I) may modulate insulin resistance further, beyond the effects of adiposity and fat distribution [53]. Crosssectional studies have shown that puberty is linked to a reduction in insulin sensitivity $[54,55]$. In a serial study of 60 children spanning the pubertal transition from Tanner stages I to III, there was a reduction in insulin sensitivity by approximately one-third, and an increase in fasting blood glucose and insulin [56]. The fall in insulin sensitivity was not associated with changes in body fat, visceral fat, IGF-I, androgens or oestradiol, and these changes were similar, regardless of sex, ethnicity or obesity.

Adiponectin is a novel adipocyte-derived peptide expressed predominantly in visceral adipose tissue $[57,58]$. It is considered to have anti-diabetic, anti-inflammatory and anti-atherogenic effects, and has reduced levels in patients with coronary artery disease and diabetes mellitus in comparison with healthy people [57, 58]. Low plasma concentrations of adiponectin may be partly responsible for the atherogenic risk seen in patients with metabolic syndrome [57].

Resistin was discovered recently and is an adipocytokine expressed in human, rat and mouse adipose tissue. The resistin gene is expressed almost exclusively in adipocytes [59], with increased expression in abdominal fat [60]. It has potential roles in regulating insulin resistance and adipocyte differentiation [59,60], and may provide a possible link between central obesity and type 2 diabetes mellitus and cardiovascular disease [60].

\section{Body Composition Is a Risk Factor for Adult Diseases}

There are aspects of body composition that are risk factors for a variety of common multi-factorial diseases in adulthood. The most apparent are those that result directly from components of body composition, namely obesity (TBF) and osteoporosis (BMC and bone mineral density) $[4,8]$. As discussed above, these components tend to track over time. Adolescents who are overweight or obese during puberty are at greater risk of being overweight or obese as adults [37, 43], and those with low BMC at peak bone mass are at greater risk of subsequent osteoporosis [4].
Similarly, lifetime overweight and obesity are major risk factors for cardiovascular disease in adults [42, 61]. There are also strong relationships in children between body composition and risk factors for cardiovascular disease, such as blood pressure. For example, a difference between the sexes in the relationship between blood pressure and trunk fat was observed in a study of 920 African-American, Asian and Caucasian children aged 5 to 18 years [62]. Using DXA and skinfold measurements, significant positive relationships between systolic and diastolic blood pressure and trunk fat, adjusted for TBF, were seen in boys at all pubertal stages in the three ethnic groups. In girls, however, trunk fat was not a significant predictor of blood pressure.

\section{Body Composition during Puberty}

A negative relationship between age at menarche, BMI and body fatness in girls has been shown [63-65]. It is still unclear, however, whether increased early childhood adiposity induces an earlier onset of puberty, if rapid maturation and early puberty induce an increase in body fat later in life, or whether both of these phenomena occur. In preliminary studies, we examined growth, maturation and body composition using serial data from 5,082 observations of a subset of 242 Causasian girls in the Fels Longitudinal Study, who were born between 1929 and 1982 (i.e. girls for whom there were data until the minimum age of 21 years) [66]. Secular trends in body composition have emerged over the past few decades (e.g. increases in adiposity), and so we hypothesized that insight into the relationships between serial indicators of maturation and body composition could be gained by examining data from children who were born at different times during the last century. The girls selected had an average of 21 serial

Table 1. Sample size and mean age in years (standard deviation) by cohort at specific developmental landmarks from pre- to post-puberty

\begin{tabular}{lccc}
\hline Developmental landmark & $\mathrm{n}$ & $\begin{array}{l}\text { Cohort 1 } \\
(1929-1954)\end{array}$ & \multicolumn{1}{c}{$\begin{array}{l}\text { Cohort 2 } \\
(1955-1982)\end{array}$} \\
\hline Age at early childhood MHV & 150 & $3.8(0.7)$ & $3.8(0.7)$ \\
Age at pre-pubertal MHV & 242 & $9.2(0.8)$ & $9.2(0.8)$ \\
Age at adolescent PHV & 242 & $11.6(0.9)$ & $11.4(0.9)$ \\
Age at menarche & 211 & $12.7(1.1)$ & $12.6(1.3)$ \\
\hline
\end{tabular}

MHV = Minimum height velocity PHV = peak height velocity 
Fig. 2. BMI values from 6 years before menarche to 6 years after menarche in girls born between 1929 and 1954 (Cohort 1 - solid line) and those born between 1955 and 1982 (Cohort 2 - dashed line) based on the mixed effects model fitted to long-term serial data.

Table 2. Estimated mean stature and BMI ( \pm standard error) by cohort from 6 years before menarche to 6 years after menarche in girls born between 1929 and 1954 (Cohort 1) and those born between 1955 and 1982 (Cohort 2) based on a mixed effects model fitted to long-term serial data

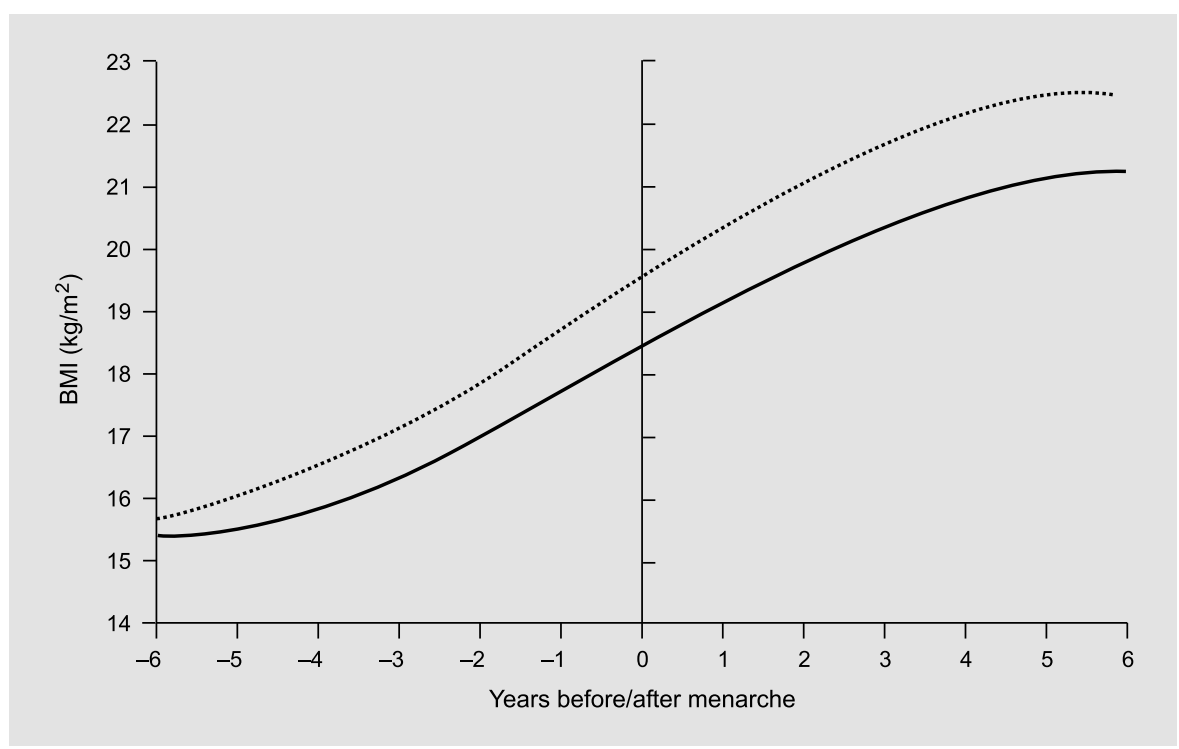

\begin{tabular}{|c|c|c|c|c|}
\hline \multirow{2}{*}{$\begin{array}{l}\text { Years before/after } \\
\text { menarche }\end{array}$} & \multicolumn{2}{|l|}{ Stature, $\mathrm{cm}$} & \multicolumn{2}{|c|}{ BMI, $\mathrm{kg} / \mathrm{m}^{2}$} \\
\hline & Cohort 1 & Cohort 2 & Cohort 1 & Cohort 2 \\
\hline-6 years & $123.8 \pm 0.6$ & $124.8 \pm 0.7$ & $15.4 \pm 0.1$ & $15.7 \pm 0.1$ \\
\hline-4 years & $137.7 \pm 0.6$ & $138.3 \pm 0.7$ & $15.9 \pm 0.2$ & $16.6 \pm 0.2^{*}$ \\
\hline-2 years & $148.8 \pm 0.6$ & $149.2 \pm 0.6$ & $17.0 \pm 0.2$ & $18.0 \pm 0.2^{*}$ \\
\hline Menarche & $157.1 \pm 0.5$ & $157.4 \pm 0.6$ & $18.4 \pm 0.2$ & $19.6 \pm 0.2^{*}$ \\
\hline+2 years & $162.6 \pm 0.5$ & $162.9 \pm 0.6$ & $19.8 \pm 0.2$ & $21.0 \pm 0.3^{*}$ \\
\hline+4 years & $165.2 \pm 0.5$ & $165.7 \pm 0.6$ & $20.8 \pm 0.3$ & $22.1 \pm 0.3^{*}$ \\
\hline+6 years & $164.8 \pm 0.5$ & $165.7 \pm 0.6$ & $21.2 \pm 0.3$ & $22.4 \pm 0.3^{*}$ \\
\hline
\end{tabular}

* Cohort 2 different from Cohort $1, \mathrm{p}<0.01$. observations each (range 6-44 observations). Age at menarche was collected prospectively at 6-month intervals.

Serial data on height, weight and BMI were analysed in two cohorts; Cohort 1 (born 1929-1954) and Cohort 2 (born 1955-1982) were followed longitudinally from 6 years before menarche to 6 years after menarche. For each girl, landmarks of growth in stature, including early childhood MHV, pre-pubertal MHV and adolescent PHV, were determined using the triple logistic model of growth (fig. 1) as implemented in the AUXAL software package [67]. The timings of several developmental landmarks from pre- to post-puberty in the two cohorts are shown in table 1 . There were no significant differences between the two cohorts (i.e. no secular trend) in attaining these landmarks, including the age at menarche. Similarly, Chumlea and colleagues have concluded that there appears to be no secular trend in the age at menarche in girls in the USA over the past few decades [31].

Longitudinal analyses were performed using mixed effects models, which considered an unstructured covariance structure, random effects (individual) and fixed effects including intercept, slope (age), acceleration (age ${ }^{2}$ ), change in acceleration $\left(\mathrm{age}^{3}\right)$, cohort, and cohort by age and cohort by age ${ }^{2}$ interactions. As shown in table 2 , there are no secular trends in stature during puberty; the two cohorts are virtually identical in terms of growth in stature [66]. There are, however, large and significant differences between the two cohorts in BMI at all time points with the exception of the earliest time point, 6 years before menarche (table 2). The BMI values across the 6 years before and after menarche in the two cohorts as fitted from the longitudinal model are shown in figure 2. Although it is not shown here, 
a similar difference between cohorts is observed for BMI velocities (i.e. the rate of change in BMI in individuals) [66]. Although BMI is not an ideal indicator of body composition in children, in the context of these analyses, the only plausible explanation for the large difference in BMI between the cohorts and no difference in stature is that greater increases in adiposity occurred during puberty in Cohort 2 compared with Cohort 1.

If the main difference in body composition between the two cohorts is the greater adiposity in Cohort 2, then tentative hypotheses about the relationship between adiposity and puberty can be made by examining indicators of maturation in the two cohorts. In spite of significantly higher BMI levels in Cohort 2 at various developmental landmarks, there are no differences between the cohorts in the timing of these landmarks [66]. Thus, to the extent that BMI is an indicator of secular increases in adiposity and considering the stability of indicators of growth patterns over time (e.g. the timing of physical growth landmarks and the age at menarche), the secular increase in BMI (adiposity) seen in the Fels Longitudinal Study from 1929 to 1982 did not have an effect on the rate of growth or sexual maturation in girls. As data from cohorts with more recent dates of birth become available, we can examine this relationship and see how it relates to the current national surge in the prevalence of obesity.

We also performed other longitudinal analyses, using random effects models applied to serial data to characterize individual-to-individual differences, allowing for fixed (same slope) or random (differing slopes) effects of age and continuous indicators of maturation on various measures of body composition. We found that children in the Fels Longitudinal Study who were more pubertally advanced than their peers, tended to be taller and have more TBF, BMC and FFM. Greater stature alone could account for greater TBF, BMC and FFM, but percentage body fat, which is largely independent of stature, was higher in girls with an earlier age of menarche and onset of puberty (as measured using Tanner staging for breast development) than their later-maturing peers.

\section{Conclusions}

Throughout the recent history of evaluating body composition and maturation during puberty, various methods of assessment have evolved. Techniques such as DXA and densitometry are better at analysing and quantifying TBF and FFM in children than BMI. A number of physiological changes occur during puberty, including rapid increases in physical size, hormonal fluctuations and marked changes in body composition, and the timing of various maturational landmarks during this period is strongly related to concurrent body composition. Furthermore, adipose tissue, as a major component of body composition, is involved in many hormonal interactions with growth and maturational factors during puberty that affect aspects of metabolic programming, including energy expenditure and insulin resistance. The majority of measures of body composition track from puberty into adulthood, and so knowledge of the relative contributions of various body components (i.e. TBF, BMC and FFM) can lead to a better understanding of the natural progression of many chronic diseases including obesity, cardiovascular disease, osteoporosis and diabetes. In addition, this knowledge allows predictions to be made about subsequent health outcomes and helps to identify ideal timing for more effective primary disease prevention.

\section{Acknowledgements}

This work was supported by grants HD-12252, HD-36342 and HD-38356 from the National Institutes of Health, Bethesda, Maryland, USA.

\section{References}

1 Pierson RN, Wang J, Thornton JC, Heymsfield SB: The quality of the body cell mass -1996 . Are we ready to measure it? Appl Radiat Isot 1998;49:429-436.

2 Maynard LM, Wisemandle W, Roche AF, Chumlea WC, Guo SS, Siervogel RM: Childhood body composition in relation to body mass index. Pediatrics 2001;107:344-350.
3 Guo SS, Chumlea WC, Roche AF, Siervogel RM: Age- and maturity-related changes in body composition during adolescence into adulthood: the Fels Longitudinal Study. Int $\mathbf{J}$ Obes Relat Metab Disord 1997;21:11671175.

4 Nguyen TV, Maynard LM, Towne B, Roche AF, Wisemandle WA, Li J, Guo SS, Chumlea WC, Siervogel RM: Sex differences in bone mass acquisition during growth: the Fels Longitudinal Study. J Clin Densitom 2001;4:147157.
5 Siervogel RM, Maynard LM, Wisemandle WA, Roche AF, Guo SS, Chumlea WC, Towne B: Annual changes in total body fat (TBF) and fat free mass (FFM) in children from 8 to 18 years in relation to changes in body mass index (BMI). The Fels Longitudinal Study. Ann NY Acad Sci 2000;904:420-423.

6 Bitar A, Vernet J, Coudert J, Vermorel M: Longitudinal changes in body composition, physical capacities and energy expenditure in boys and girls during the onset of puberty. Eur $\mathbf{J}$ Nutr 2000;39:157-163. 
7 Chumlea W, Guo SS: Assessment and prevalence of obesity: application of new methods to a major problem. Endocrine 2000;13:135142.

8 Flegal KM, Ogden CL, Wei R, Kuczmarski RL, Johnson CL: Prevalence of overweight in US children: comparison of US growth charts from the Centers for Disease Control and Prevention with other reference values for body mass index. Am J Clin Nutr 2001;73:1086-1093.

9 Himes J, Dietz W: Guidelines for overweight in adolescent preventive services: recommendations from an expert committee. The Expert Committee on Clinical Guidelines for Overweight in Adolescent Preventive Services. Am J Clin Nutr 1994:59:307-316.

10 Bellizzi MC, Dietz WH: Workshop on childhood obesity: summary of the discussion. Am J Clin Nutr 1999; 70:173S-175S

11 Ogden CL, Kuczmarski RJ, Flegal KM, Mei Z, Guo S, Wei R, Grummer-Strawn LM, Curtin LR, Roche AF, Johnson CL: Centers for Disease Control and Prevention 2000 growth charts for the United States: improvements to the 1977 National Center for Health Statistics version. Pediatrics 2002;109:45-60.

12 Ogden CL, Flegal KM, Carroll MD, Johnson CL: Prevalence and trends in overweight among US children and adolescents, 19992000. JAMA 2002;288:1728-1732.

13 Kuczmarski RJ, Ogden CL, Grummer-Strawn LM, Flegal KM, Guo SS, Wei R, Mei Z, Roche AF, Curtin LR, Johnson CL: CDC growth charts: United States. Advance data from vital and health statistics no. 314, National Center for Health Statistics 2000, pp 28.

14 Kuczmarski RJ, Flegal KM: Criteria for definition of overweight in transition: background and recommendations for the United States. Am J Clin Nutr 2000;72:1074-1081.

15 US Centers for Disease Control and Prevention (2002) CDC Growth Chart Training. National Center for Chronic Disease Prevention and Health Promotion: http://www. cdc.gov/nccdphp/dnpa/growthcharts/training/ modules/index.htm

16 Garn S, Leonard W, Hawthorne V: Three limitations of body mass index. Am J Clin Nutr 1986;44:996-997.

17 Daniels SR, Khoury PR, Morrison JA: The utility of body mass index as a measure of body fatness in children and adolescents: differences by race and gender. Pediatrics 1997;99:804807.

18 Pietrobelli A, Faith MS, Allison DB, Gallagher D, Chiumello G, Heymsfield SB: Body mass index as a measure of adiposity among children and adolescents: a validation study. J Pediatr 1998; 132:204-210.

19 Roche A, Siervogel R, Chumlea WC, Webb P: Grading body fatness from limited anthropometric data. Am J Clin Nutr 1981;34:28312838

20 Warner JT, Cowan FJ, Dunstan FDJ, Gregory JW: The validity of body mass index for the assessment of adiposity in children with disease states. Ann Human Biol 1997;24:209215.
21 Lazarus R, Baur L, Webb K, Blyth F: Body mass index in screening for adiposity in children and adolescents: systematic evaluation using receiver operating characteristic curves. Am J Clin Nutr 1996;63:500-506.

22 Demerath EW, Guo SS, Chumlea WC, Towne B, Roche AF, Siervogel RM: Comparison of percent body fat estimates using air displacement plethysmography and hydrodensitometry in adults and children. Int J Obes Metab Disord 2002;26:389-397.

23 McCrory MA, Mole PA, Gomez TD, Dewey KG, Bernauer EM: Body composition by airdisplacement plethysmography by using predicted and measured thoracic gas volumes. J Appl Physiol 1998;84:1475-1479.

24 Bachrach LK: Dual energy X-ray absorptiometry (DEXA) measurements of bone density and body composition: promise and pitfalls. J Pediatr Endocrinol Metab 2000;13:983-988.

25 Chumlea WC, Guo SS, Kuczmarski RJ, Flegal KM, Johnson CL, Heymsfield SB, Lukaski HC, Friedl K, Hubbard VS: Body composition estimates from NHANES III bioelectrical impedance data. Int J Obes Relat Metab Disord 2002;26:1596-1609.

26 Wang ZM, Zhu SK, Wang J, Pierson RN, Heymsfield SB: Whole-body skeletal muscle mass: development and validation of totalbody potassium prediction models. Am J Clin Nutr 2003;77:76-82.

27 Despres J: The insulin resistance-dyslipidemic syndrome of visceral obesity: effect on patients' risk. Obes Res 1998;6:8S-17S.

28 Kissebah A: Intra-abdominal fat: is it a major factor in developing diabetes and coronary artery disease? Diabetes Res Clin Pract 1996;30: 25-30.

29 Montague C, O'Rahilly S: The perils of portliness: causes and consequences of visceral adiposity. Diabetes 2000;49:883-888.

30 Sun S, Schubert CM, Chumlea WC, Roche AF, Kulin HE, Lee PE, Himes JH, Ryan AS: National estimates of the timing of sexual maturity and racial differences among US children. Pediatrics 2002;110:911-919.

31 Chumlea WC, Schubert CM, Roche AF, Kulin HE, Lee PA, Himes JH, Sun S: Age at menarche and racial comparisons in US girls. Pediatrics 2003;111:110-113.

32 Roche AF: Assessing the utility of Fels handwrist skeletal age assessments. Am J Phys Anthropol 1988;75:262.

33 Towne B, Blangero J, Parks JS, Brown MR, Roche AF, Siervogel RM: Analytic approaches to the study of genetic influences on normal skeletal maturation; in Gilli G, Schell LM, Benso L (eds): Human Growth from Conception to Maturity. London, Smith-Gordon, 2002, pp 113-123.

34 Iuliano-Burns S, Mirwald RL, Bailey DA: Timing and magnitude of peak height velocity and peak tissue velocities for early, average, and late maturing boys and girls. Am J Human Biol 2001;13:1-8

35 Garn S, Lavelle M, Rosenburg K, Hawthorne $\mathrm{V}$ : Maturational timing as a factor in female fatness and obesity. Am J Clin Nutr 1986;43: 879-883.
36 Van Lenthe F, Kemper C, Van Mechelan W: Rapid maturation in adolescence results in greater obesity in adulthood: the Amsterdam Growth and Health Study. Am J Clin Nutr 1996;64:18-24.

37 Guo S, Wu W, Chumlea WC, Roche AF: Predicting overweight and obesity in adulthood from body mass index values in childhood and adolescence. Am J Clin Nutr 2002;76:653658.

38 Guo SS, Huang C, Maynard LM, Demerath E, Towne B, Chumlea WC, Siervogel RM: Body mass index during childhood, adolescence and young adulthood in relation to adult overweight and adiposity: the Fels Longitudinal Study. Int J Obes Relat Metab Disord 2000;24: 1628-1635.

39 Holst D, Grimaldi PA: New factors in the regulation of adipose differentiation and metabolism. Curr Opin Lipidol 2002;13:241-245.

40 Horlick MB, Rosenbaum M, Nicolson M, Levine LS, Fedun B, Wang J, Pierson RN, Leibel RL: Effect of puberty on the relationship between circulating leptin and body composition. J Clin Endocrinol Metab 2000;85:2509-2518.

41 Chumlea WC, Wisemandle W, Guo SS, Siervogel RM: Relations between frame size and body composition and bone mineral status. Am J Clin Nutr 2002;75:1012-1016.

42 Siervogel RM, Wisemandle WA, Maynard LM, Guo SS, Chumlea WC, Towne B: Lifetime overweight status in relation to serial changes in body composition and risk factors for cardiovascular disease: the Fels Longitudinal Study. Obes Res 2000;8:422-430.

43 Wisemandle W, Maynard LM, Guo SMS, Siervogel RM: Childhood weight, stature, and body mass index among never overweight, earlyonset overweight, and late-onset overweight groups. Pediatrics 2000;106:U29-U36.

44 Harsha DW, Smoak CG, Nicklas TA, Webber LS, Berenson GS: Cardiovascular risk factors from birth to 7 years of age: the Bogalusa Heart Study. Tracking of body composition variables. Pediatrics 1987;80:779-783.

45 Huang TT, Johnson MS, Figueroa-Colon R, Dwyer JH, Goran MI: Growth of visceral fat, subcutaneous abdominal fat, and total body fat in children. Obes Res 2001;9:283-289.

46 Salbe AD, Weyer C, Lindsay RS, Ravussin E, Tataranni PA: Assessing risk factors for obesity between childhood and adolescence: I. Birth weight, childhood adiposity, parental obesity, insulin, and leptin. Pediatrics 2002;110:299_ 306.

47 Janeckova R: The role of leptin in human physiology and pathophysiology. Physiol Res 2001; 50:443-459.

48 Remsberg KE, Talbott EO, Zborowski JV, Evans RW, McHugh-Pemu K: Evidence for competing effects of body mass, hyperinsulinemia, insulin resistance, and androgens on leptin levels among lean, overweight, and obese women with polycystic ovary syndrome. Fertil Steril 2002;78:479-486.

49 Ellis K, Nicolson M: Leptin levels and body fatness in children: effects of gender, ethnicity, and sexual development. Pediatr Res 1997;42: 484-488. 
50 Demerath EW, Towne B, Wisemandle W, Blangero J, Chumlea WC, Siervogel RM: Serum leptin concentration, body composition, and gonadal hormones during puberty. Int $\mathrm{J}$ Obes 1999;23:678-685.

51 Ahmed ML, Ong KKL, Morrell DJ, Cox L, Drayer N, Perry L, Preece MA, Dunger DB: Longitudinal study of leptin concentrations during puberty: sex differences and relationship to changes in body composition. J Clin Endocrinol Metab 1999;84:899-905.

52 Rosenbaum M, Pietrobelli A, Vasselli JR, Heymsfield SB, Leibel RL: Sexual dimorphism in circulating leptin concentrations is not accounted for by differences in adipose tissue distribution. Int J Obes 2001;25:1365-1371.

53 Roemmich JN, Clark PA, Lusk M, Friel A Weltman A, Epstein L, Rogol AD: Pubertal alterations in growth and body composition. VI. Pubertal insulin resistance: relation to adiposity, body fat distribution and hormone release. Int J Obes 2002;26:701-709.

54 Bloch C, Clemons P, Sperling M: Puberty decreases insulin sensitivity. J Pediatr 1987;110: 481-487.

55 Potau N, Ibanez L, Rique S, Carrascosa A: Pubertal changes in insulin secretion and peripheral insulin sensitivity. Horm Res 1997;48: 219-226.
56 Goran MI, Gower BA: Longitudinal study on pubertal insulin resistance. Diabetes 2001;50: 2444-2450.

57 Matsubara M, Maruoka S, Katayose S: Decreased plasma adiponectin concentrations in women with dyslipidemia. J Clin Endocrinol Metab 2002;87:2764-2769.

58 Nishizawa H, Shimomura H, Kishida K, Maeda N, Kuriyama H, Nagaretani H, Matsuda M, Kondo H, Furuyama N, Kihara S, Nakamura T, Tochino Y, Funahashi T, Matsuzawa Y: Androgens decrease plasma adiponectin, an insulin-sensitizing adipocyte-derived protein. Diabetes 2002;51:2734-2741.

59 Hartman HB, Hu X, Tyler KX, Dalal CK, Lazar MA: Mechanisms regulating adipocyte expression of resistin. J Biol Chem 2002;277: 19754-19761.

60 McTernan PG, McTernan CL, Chetty R, Jenner K, Fisher FM, Lauer M, Crocker J, Barnett $\mathrm{AH}$, Kumar S: Increased resistin gene and protein expression in human abdominal adipose tissue. J Clin Endocrinol Metab 2002;87:24072410 .
61 Siervogel RM, Wisemandle WA, Maynard LM, Guo SS, Roche AF, Chumlea WC, Towne B: Serial changes in body composition throughout adulthood and their relationships to changes in lipid and lipoprotein levels: the Fels Longitudinal Study. Arterioscler Thromb Vasc Biol 1998;18:1759-1764.

62 He Q, Horlick M, Fedun B, Wang J, Pierson RN Jr, Heshka S, Gallagher D: Trunk fat and blood pressure in children through puberty. Circulation 2002;105:1093-1098.

63 Tanner J: Growth at Adolescence. Oxford, Blackwell Scientific Publications, 1955.

64 Buckler J: A Longitudinal Study of Adolescent Growth. Heidelberg, Springer-Verlag, 1990.

65 Van Lenthe FJ, Kemper HC, Van Mechelen W, Post GB, Twisk JW, Welten DC, Snel J: Biological maturation and the distribution of subcutaneous fat from adolescence to adulthood: the Amsterdam Growth and Health Study. Int J Obes Relat Metab Disord 1996;20:121-129.

66 Demerath EW, Li J, Towne B, Guo SS, Chumlea WC, Siervogel RM: Secular changes in the pattern of BMI increase during puberty: the Fels Longitudinal Study. Am J Hum Biol 2002; 14:109.

67 Bock RD, Du Toit SHC, Thissen D: AUXAL: Auxological Analysis of Longitudinal Measurements of Human Stature. Chicago, Scientific Software International, Inc., 1994. 